\title{
El problema del hombre en la fenomenología de Husser ${ }^{1}$
}

\section{The problem of man in the phenomenology of Husserl}

\author{
Rubén Sánchez Muñoz \\ Universidad Popular Autónoma del Estado de Puebla, México
}

\begin{abstract}
Resumen: En este trabajo se explora la relación que existe entre la fenomenología trascendental y la antropología. El autor sostiene que puede haber desde el interior de la reducción trascendental la justificación y validez de una antropología trascendental que aparece de manera implícita en los textos de Husserl. La respuesta de Husserl al problema del hombre consistiría entonces en afirmar que el ser humano no es un hecho de la naturaleza sino un sujeto trascendental, un sujeto racional en todo su sentido, a partir del cual se constituye todo fenómeno de ser. Para poder sostener esta tesis se distingue entre dos niveles de subjetividad o dos dimensiones del ser humano: como ser mundano y como sujeto trascendental; se afirma que desde la trascendentalidad del ser humano se puede pensar en la posibilidad de una antropología trascendental que recupera el sentido racional, trascendental, del hombre, sin traicionar el sentido de la reducción trascendental.
\end{abstract}

Palabras clave: fenomenología trascendental, antropología, reducción, ser humano, sujeto trascendental, constitución, sentido, epojé.

Abstract: In this paper the relationship between transcendental phenomenology and anthropology is explored. The author argues that there may

${ }^{1}$ Este trabajo es resultado de mi Estancia Posdoctoral en la Maestría en Filosofía de la Facultad de Filosofía y Letras de la Benemérita Universidad Autónoma de Puebla, México, a través del apoyo del CONACyT. Agradezco al profesor Roberto Walton la lectura atenta y las valiosas recomendaciones hechas a este texto. 
be from with in the transcendental reduction justification and validity of a transcendental anthropology which implicitly appears in the texts of Husserl. Husserl's answer to man's problem then would be to say that the human being is not a fact of nature but a transcendental subject, a rational subject in all its meaning, from which all phenomena of being constituted. In order to sustain this thesis, it distinguishes between two levels of subjectivity or two dimensions of the human being: as being mundane and as transcendental subject; It states that from the transcendence of the human being can think about the possibility of a transcendental anthropology that recovers the transcendental, rational sense of man, without betraying the meaning of the transcendental reduction.

Keywords: Transcendental phenomenology, Anthropology, Reduction, Human being, Transcendental subject, Constitution, Meaning, Epojé.

\section{Introducción}

- ${ }^{l}$ problema que expongo en este trabajo es el siguiente: ¿qué Clugar ocupa el ser humano dentro de la fenomenología trascendental? La pregunta ya supone de alguna manera una respuesta por parte de Husserl. No se trata de un asunto sencillo, sino de uno de esos problemas que requieren mucha atención y cuidado, porque de la solución que se dé dependerá, o puede llegar a depender, el sentido mismo de la fenomenología trascendental y la función o tarea de la fenomenología y del fenomenólogo, e incluso esta respuesta puede tener un gran alcance en el esfuerzo de fundamentación y clarificación de la antropología y de la psicología como ciencias. En este trabajo se presenta resumidamente la respuesta de Husserl a la pregunta por el ser humano, aunque ciertamente el problema puede abordarse desde distintos escorzos o perspectivas y no siempre en el mismo sentido, sino a través de matices que, como veremos, van ampliando los puntos de vista. En todo caso, se trata de presentar esos puntos de vista para posteriormente someterlos a revisión. 
En las páginas que siguen, en un primer momento, presento algunas precisiones metodológicas en las que se deja ver sucintamente la postura de Husserl respecto de la filosofía entendida como fenomenología; por tanto, la necesidad de practicar en filosofía la reducción trascendental. Dicho esto, nos introducimos en el análisis de la idea del hombre que se requiere poner entre paréntesis en la fenomenología husserliana y, por tanto, en una respuesta parcial de por qué la fenomenología no es antropología. Acto seguido, expondremos lo que pasa con esa idea de ser humano durante la reducción trascendental; es decir, cómo el ser humano, al igual que cualquier otro ser, se constituye en y para la conciencia intencional a partir de la cual cobra sentido y validez de ser. Una vez trazado este camino, intentaremos fundamentar el sentido del ser humano y la posibilidad de una dimensión antropológica de la fenomenología trascendental desde el interior de la reducción trascendental, apuntando, por último, al sentido práctico de la reducción trascendental, el que resulta a nuestro juicio el más importante de todos, pero que, por lo mismo, expondremos en otro trabajo.

\section{Precisiones metodológicas}

A lo largo de su vida, Husserl insistió una y otra vez en que la falta de comprensión de la reducción trascendental era la causa principal de los errores y malos entendidos de la fenomenología y su carácter científico. Por esta línea pasaron varios de sus estudiantes y allegados, pero especialmente Husserl se refirió en la década de los treinta a dos: Scheler y Heidegger, quienes habían logrado desarrollar aspectos importantes de la fenomenología que eran posibles de aplicar a la antropología filosófica. Éste no es el lugar de entablar un diálogo con Scheler, Heidegger u otros fenomenólogos para hacer justicia al trabajo que realizaron y aclarar el sentido de esos trabajos a la luz del desarrollo y despliegue de la fenomenolo- 
gía en ese momento. Lo que se quiere hacer por ahora es mostrar que la postura de Husserl respecto de un saber sobre el ser humano siempre fue contundente y radical. Pero ello tiene algunos presupuestos, o si no se les quiere llamar así, digamos que esas críticas se fundan en algunas ideas sobre el ser humano en ese contexto. No está demás mostrar esta patencia que, además, a estas alturas no debe sorprender a nadie.

En el $\$ 12$ de Ideas III, por ejemplo, Husserl dijo tajantemente, al hablar del psicólogo y de aquel que quiere hacer filosofía, que si no logra liberarse de los prejuicios no podrá ser un verdadero filósofo, "hará una filosofía superficial y parirá un mal engendro, mitad ciencia natural y mitad filosofía" (Husserl, 2014: 87; Hua V, 74). ${ }^{2}$ Porque el filósofo debe poner las cosas en claro de una manera rigurosa si es que en verdad quiere ser filósofo. Es más, allí mismo afirma que "Quien no sea capaz de liberarse de esta particular apercepción, quien no pueda ejecutar las reducciones fenomenológicas y captar la vivencia pura, tampoco podrá penetrar en la fenomenología trascendental ni en la filosofía" (Husserl, 2014: 87; Hua V, 74). Claro está que en este pasaje Husserl intenta clarificar el sentido de algunos términos que son afines a la psicología y a la fenomenología, pero los cuales no siempre tienen el mismo significado en un lado y en otro, tales como conciencia (Bewusstsein), vivencia (Erlebnis), psique, entre otros. Aquí, por ejemplo, ya está marcada una línea de convergencia entre el quehacer fenomenológico y la psicología. Dependiendo la postura que se asuma y las tesis que se deseen defender, las líneas de interés, de convergencia o de divergencia, podrían fácilmente ampliarse a otras disciplinas, tales como la neurociencia, el psicoanálisis, entre otras.

${ }^{2}$ En lo que sigue, citaremos como Hua la edición Husserliana de las obras de Edmund Husserl seguido del volumen del tomo y el número de página. En cada caso las citas han sido confrontadas con la traducción al español como se indica al inicio de cada referencia. 
Pues bien, ante cualquier postura, cabe tener presente que uno de los objetivos de la fenomenología consiste en fundamentar la validez de los juicios de "intuiciones originariamente dadoras" (Husserl, 2013: 120; Hua III/I, 42). Esta pretensión de clarificación y búsqueda de evidencia, lo cual está contenido también en las ciencias, es ya una búsqueda de legitimación y de racionalidad. La fenomenología aspira a ser ciencia rigurosa (strenge Wissenschaft), ello significa que tiene que ser crítica de sí misma y fundamentarse a sí misma, por esta razón no puede asumir los juicios de ninguna ciencia hasta cerciorarse de la validez de los mismos en persona, porque "por obra de los prejuicios se vuelve uno incapaz de traer al campo del juicio lo que tiene en el campo de la propia intuición" (Husserl, 2013: 126; Hua III/I, 48).

Esta exigencia de racionalidad y esta búsqueda constante de clarificación es justamente la tarea del filósofo; ello lo obliga a no quedarse solamente atrapado en la esfera de su propia disciplina, pues le viene exigida de manera categórica la revisión de los conceptos de otras ciencias: sus conceptos fundamentales, sus métodos y procedimientos y las implicaciones prácticas. La tarea de la fenomenología no consiste en ser juez o árbitro de las demás ciencias, si alguien ha sostenido una tesis como ésta, es necesario revisarla y evaluar su validez y su sentido. Las ciencias, cada una por su lado, están exigidas, como lo está la misma filosofía, a elevar al nivel más alto posible de clarificación sus propios fundamentos, conceptos, métodos, etc., y están llamadas a emprender críticamente sus respectivos trabajos. Si la fenomenología puede interferir en esta tarea que, como ya se ha dicho, compete estrictamente a cada ciencia, eso es algo que todavía tenemos que evaluar, porque finalmente la propia fenomenología se ha desplegado históricamente, padeciendo el infortunio de su propia incomprensión, no sólo en las esferas ajenas al quehacer científico, sino al interior mismo de su propia actividad. 
En el Epílogo a Ideas I, de 1930, dijo Husserl que las objeciones en contra de la fenomenología radican en el hecho de que "no se ha entendido lo por principio novedoso de la "reducción fenomenológica” y, por ende, el ascenso desde la subjetividad mundana (el hombre) a la "subjetividad trascendental". El problema, prosigue Husserl, es que "se permanece atascado en una antropología, sea empírica o apriórica, la que según mi doctrina no alcanza todavía en absoluto el terreno absolutamente filosófico, y tomar la cual por filosofía significa una recaída en el "psicologismo" o el "antropologismo trascendental" (Husserl, 2013: 467; Hua III/2, 140). Pues bien, esta declaración ha de servirnos de punto de partida en el esclarecimiento del problema que nos compete. La fenomenología aspira a ser ciencia radical, la más radical, la ciencia primera, y por ello debe esclarecer sus propios fundamentos.

Al hacerlo, distingue entre dos niveles de subjetividad en la que puede enmarcarse de inicio la relación o la reflexión de la fenomenología sobre el ser humano -sobre la psicología, a la que esa idea misma de ser humano pertenece-. Por un lado, la subjetividad mundana desde un punto de vista tanto empírico-natural como eidético y, por otro lado, la subjetividad trascendental, posible de descubrir sólo a través de la reducción trascendental. También podríamos decir que, por un lado pre-trascendental, aparece el ser humano como hecho en el mundo, como realidad factual y, por otro lado, ya en un nivel trascendental, aparece la subjetividad bajo aspectos que se suponen novedosos y desde el cual, a juicio de Husserl, se debe desarrollar cualquier tarea fundante en el horizonte de una crítica de la razón. Quedarse en el primer nivel, esto es en el nivel de la subjetividad mundana, significa ipso facto no haber comprendido el sentido y alcance de la reducción trascendental -de la cual afirmó Eugen Fink ser el método fundamental de la fenomenología-. Acceder al nivel trascendental significa suprimir (aufheben) o desconectar (ausschalten) la validez del ser humano 
como trascendencia, ponerla entre paréntesis o lo que es lo mismo practicar la epojé para reducir o re-con-ducir la reflexión filosófica al interior de las propias operaciones de la conciencia. También implica, en cierto sentido, la posibilidad misma de la fenomenología en dos facetas importantes que hay que distinguir. La fenomenología como ciencia eidética y, más allá, la fenomenología como ciencia de la subjetividad trascendental. En un panorama más amplio, pero sobre el cual no es posible profundizar en este momento, estaría contenida la distinción entre una fenomenología estática y una fenomenología genética (cfr. Walton, 2015: 45ss).

\section{Niveles de reflexión sobre el ser humano}

El problema del hombre es un problema que concierne a la fenomenología desde el punto de vista de una determinada idea del hombre, desde una antropología que está detrás de algunas teorías científicas que Husserl atacó radicalmente, por lo menos de manera explícita desde las lecciones de Göttingen de 1907. Por ejemplo, esta preocupación aparece claramente en La idea de la fenomenología, cuando Husserl recuerda la moderna teoría de la evolución y sus consecuencias epistemológicas, pero al mismo tiempo la idea de hombre que está latente en dicha teoría:

Recordamos la moderna teoría de la evolución, según la cual el hombre se ha desarrollado en la lucha por la existencia y merced a la selección natural; $y$, claro es, con el hombre, también su intelecto, y con el intelecto, a su vez, todas las formas que le son propias, es decir, las formas lógicas. ¿¿No expresan, por lo tanto, las formas y leyes lógicas la peculiar índole contingente de la especie humana, que podría ser de otro modo, y que será otra en el curso de la evolución futura? El conocimiento es, pues, tan sólo conocimiento humano, ligado a las formas intelectuales humanas, imposible de 
alcanzar la naturaleza de las cosas mismas, de las cosas en sí (Husserl, 1982: 30; Hua II, 21).

En su libro La nueva imagen de Husserl, Javier San Martín expone las consecuencias epistemológicas del evolucionismo y las críticas de Husserl a este planteamiento que termina teniendo consecuencias prácticas fatales para la ciencia y para la humanidad (San Martín, 2015: 134-139). Sabemos, en efecto, que uno de los problemas fundamentales de la fenomenología es el del conocimiento, pero en este caso particular aparece el problema ligado al hecho de que el conocimiento es una actividad humana. Detrás de estas posturas epistemológicas -que Husserl venía combatiendo desde Investigaciones Lógicas (1900-1901) al atacar el psicologismo- está presupuesta una idea de hombre: el hombre como trascendencia y exterioridad, el hombre como producto del azar. Así, que el ser humano sea una trascendencia quiere decir que, como cualquier otro objeto, es dudoso que nos sea dado en modo absoluto, que nos representamos como seres externos a la conciencia y, por ello, teniendo el sentido de mera exterioridad. En un sentido más amplio todavía, la trascendencia remite a la referencia que desde la inmanencia se hace sobre cualquier objeto trascendente. Husserl habla así, de una "trascendencia en la inmanencia", y es justamente este el nivel donde aparece el verdadero problema del conocimiento.

Javier San Martín ha sido muy puntual en esta línea al señalar que el problema epistemológico está latente en la obra de Husserl y que éste concierne a la idea misma de razón y de racionalidad en la que quiere fundarse la ciencia. La crisis epistemológica en la que emerge la fenomenología es, en el fondo, una crisis antropológica que se fundamenta en una crisis del ser humano, de su idea de sujeto racional. Por ello mismo, de una idea errónea de ser humano se sigue una errónea teoría del conocimiento, en consecuencia, una idea equivocada de la verdad y una idea peor aún de razón y racionalidad (San Martín, 2005: 67; 1994: 169ss). Reyes 
Mate, por su parte, reconoce que el psicologismo "se apoyaba en una visión del hombre -en una antropología- en la que se había establecido que el ser humano era mera facticidad, un resultado de hechos físicos". Y añade que esta visión del hombre tenía graves consecuencias para la libertad, la razón y en general "para cualquier proyecto racional de humanidad" (Mate, 1992: 10).

Cabe recordar que el mismo Husserl expuso en sus Prolegómenos a la lógica pura el antropologismo latente en el psicologismo, cuya tesis principal decía que toda verdad tiene "su origen exclusivo en la constitución de la especie humana" (Husserl, 2006: 115; Hua XVIII, 126). Hay que insistir en que el problema está en que la idea misma de razón que está en juego, ya que se trata de una idea factual y azarosa, según la cual la razón puede dejar de ser lo que es en cualquier momento. Lo mismo ocurre, en consecuencia, con la verdad, el bien y, en general, con todas las ideas o ideales que pueden llegar a fungir como polos de atracción de la subjetividad trascendental desde su horizonte teleológico. Las ciencias naturales no pueden ser una morada segura para la fundamentación y esclarecimiento del problema del conocimiento, según los análisis de Husserl, porque una vez que reflexionamos en los presupuestos de la ciencia natural nos vemos envueltos en "extravíos y perplejidades", en sinsentidos que conducen a "incompatibilidades y hasta en contradicciones” (Husserl, 1982: 31; Hua II, 21). La crítica de la razón teórica hace manifiesto que el conocimiento natural no sólo está fundado en opiniones falsas sobre la esencia del conocimiento, sino que, además, su interpretación del ser humano como sujeto de conocimiento tiene su origen en interpretaciones o preconcepciones erróneas. Esto desde la crítica de la razón teórica, pero vale decir que el proyecto general de la fenomenología no se queda sólo en el nivel teórico, sino que, desde allí, se desplaza y extiende a la crítica de la razón práctica y a la razón estimativa. No se trata para nada de tres razones distintas, sino de la misma razón 
vista desde tres puntos de vista o modos, y los cuales no se separan, sino que están co-implicadas en cada momento.

La crisis de las ciencias, no sólo naturales, sino también de las ciencias formales, como era el caso de la lógica, atraviesa la obra de Husserl desde Logische Untersuchungen (1900-1901) hasta Die Krisis (1936), pasando por Ideen I (1913). Y a la altura de Krisis nos encontramos ya en la primera parte la declaración de esta amenaza en la que se encuentra la filosofía de "sucumbir frente al escepticismo, al irracionalismo y al misticismo" (Husserl, 2008: 47; Hua VI, 1). Es decir, la filosofía se encuentra todavía hoy ante la amenaza de ceder a la mera opinión, de renunciar a su exigencia de radicalidad y clarificación; en pocas palabras, está a punto de renunciar a su cientificidad o, peor aún, podría decirse todavía que en algunos casos las filosofías ya renunciaron a este fin.

En el $\$ 2$ de Krisis, Husserl anticipa su preocupación frente al hecho de que los hombres modernos -refiriéndose específicamente al giro de las ciencias a finales del siglo XIX-se dejan "determinar y cegar por las ciencias positivas", lo cual ha traído como consecuencia "el alejamiento indiferente de las preguntas que son decisivas para una auténtica humanidad" (Husserl, 2008: 50; Hua VI, 4). En efecto: "Meras ciencias de hechos hacen meros seres humanos de hechos" (Husserl, 2008: 50; Hua VI, 4). Entre estas preguntas, Husserl apuntó como una de las más importantes aquellas por el sentido o el sinsentido de la existencia humana. En pocas palabras, tarde o temprano la fenomenología, o mejor aún la comunidad de los filósofos, de los fenomenólogos, tiene que enfrentarse a la pregunta sobre la función de la filosofía, del quehacer de la filosofía de cara a los problemas concretos del mundo entorno, a la vida que vivimos en comunidad y a las relaciones culturales. Es la realidad la que se impone con sus problemas, la que obliga a la meditación, a la reflexión radical sobre ella. Pero cabe la posibilidad de que la sola reflexión no sea suficiente, que sea necesario hacer más. Vivir 
en orientación ética, persiguiendo las metas más altas y los valores más altos, puede ser y de hecho ya es un punto de partida radical. Y allí la actividad filosófica y la actividad científica encuentran un mismo punto de partida, un mismo principio.

Pues bien, no tenemos que ir más lejos, aunque bien podríamos, para darnos cuenta la idea de ser humano que Husserl critica y la cual le parece ser un peligro. Es esta idea de ser humano como perteneciente a la cadena evolutiva, un ser de hechos. También podríamos decir: el ser humano como trascendencia, como parte del mundo en el sentido antes expuesto. Esta antropología, y sus consecuencias epistemológicas y por supuesto prácticas (como puede verse en las críticas al psicologismo ético contenidas en las Vorlesungen über Ethik und Wertlehre 1908-1914, (Hua XXVIII, especialmente el $\$ 4$ ), es precisamente la idea del ser humano con la cual Husserl no quiere identificar en absoluto la fenomenología trascendental. Y no sólo por sus consecuencias teóricas, sino porque justo de ello se derivan consecuencias prácticas. Esta idea o imagen del hombre puede llegar a formar parte esencial de una fenomenología eidética y, en consecuencia, de una ontología regional: la que concierne a la antropología científica, por ejemplo. Pero no así, precisamente, desde la fenomenología trascendental que intenta superar esta imagen del hombre.

En este sentido la fenomenología trascendental no es antropología y esto es justo lo que le permite a Husserl excluir "todas las interpretaciones trascendentes de los datos inmanentes, incluso aquellas que hacen de ellos «actividades y estados psíquicos» de un yo real" (Husserl, 2006: 28; Hua XVIII, 13). En efecto, las descripciones de la fenomenología, afirma Husserl, "no se refieren a las vivencias o a las clases de vivencias de personas empíricas; pues la fenomenología no sabe nada ni sospecha nada de las personas, de las vivencias mías y ajenas; la fenomenología no plantea cuestiones, ni intenta determinaciones, ni hace hipótesis sobre nada 
semejante" (2006: 29; Hua XVIII, 13). En Erste Philosophie II, volverá a insistir en que el sujeto de la experiencia fenomenológica no es "el hombre y la persona humana" (Hua VIII, 417). Pero no hay que quedarse con estas ideas y pensar en la fenomenología como una ciencia abstracta, alejada de la realidad, de la sociedad y en general del mundo entorno. En el punto de partida de la meditación filosófica con su esfuerzo de radicalidad científica está ya contenido un horizonte práctico: la preocupación por las consecuencias prácticas de la teoría. Las teorías científicas no son sólo eso, tienen un alcance mayor del esperado o del ni siquiera imaginado. De la idea de hombre que nos hacemos depende también nuestro trato con los hombres, nuestro modo de verlos y actuar; y de nuestra idea de la conciencia, o de la mente o psique, se siguen comportamientos, orientaciones en la investigación, pero también prácticas científicas determinadas que tienen impacto en el mundo social y cultural en su conjunto. Y esto evidentemente vale para todas las esferas científicas que podamos imaginar, tanto en las ciencias humanas o sociales como en las ciencias naturales.

Desde un punto de vista científico, Husserl atacó la naturalización de la conciencia, tal como la denunció en su artículo de 1910-11: Die Philosophie als strenge Wissenschaft. Criticó estas ideas porque esa es justamente la tarea de la filosofía y cabe la posibilidad de que las ciencias particulares no puedan ver las consecuencias de sus supuestos y de sus prácticas. De allí puede decirse que su "crítica positiva", como él mismo la llamó, se basó fundamentalmente en la psicología de su tiempo -y la cual por cierto no ha cambiado mucho o nada-. Husserl critica la antropología como ciencia que pertenece a la psicología, como ciencia natural que asume los presupuestos de la psicología empírica de la época y el respectivo método científico y, en consecuencia, cuando pone entre paréntesis al ser humano y dice, como lo hace en Las conferencias de Londres: "yo, en tanto ego absoluto no soy, naturalmente, 
este hombre" (Husserl, 2012: 37; cfr. Hua XXXV), está pensando en una idea naturalizada del hombre, que es la idea que hay que superar. Sólo que esta idea naturalizada del ser humano se ha inscrito en el horizonte más amplio de la naturalización del mundo y, por tanto, del empobrecimiento del mismo a través de un proceso de abstracción.

La inhibición, puesta entre paréntesis o suspensión, a la que invita la fenomenología desde el punto de vista de la antropología debe practicarse en referencia a cualquier posición naturalista y mundana respecto del ser humano visto sólo como facticidad, y no porque no lo sea, sino más bien porque no sólo es eso. Aquí las palabras "naturalmente" y "natural" tienen una referencia directa a "ciencias de la naturaleza", a las cuales pertenece, en este sentido, la misma psicología. El naturalismo era para Husserl un gran peligro desde el punto de vista teórico, pero al mismo tiempo, desde el punto de vista de la praxis, representaba a sus ojos "un peligro creciente para nuestra cultura" (Husserl, 2009a: 14; cfr. Hua XXV, 8). Por esta razón, vio como tarea urgente llevar a cabo una crítica radical de la filosofía naturalista con miras a devolverle a la filosofía su verdadera orientación científica.

\section{El ser humano como unidad intencional}

La fenomenología intenta superar una idea de hombre que está cimentada sobre la base de los prejuicios del positivismo y del naturalismo: intenta superar la idea del hombre como parte de la naturaleza y como hecho. También podríamos decir que intenta "deconstruir" esa idea de hombre. Es un trabajo de "desmontaje, la disyunción o el de-sellar lo que la tradición filosófica selló. Deconstruyendo no se destruye esta tradición -afirma Andrea Potestà-, sino que se pone a la luz lo que la tradición escondió y tapió, se abre la comprensión filosófica al gesto fundacional del edificio 
de un modo consciente" (2013: 7ss). Pero, ¿qué ocurre con el ser humano tras la epojé y cómo puede abordarse esta problemática desde la reducción trascendental?

En pleno ejercicio de la reducción, no eidética sino trascendental, el ser humano es una parte del mundo espacio-temporal que tiene un sentido meramente intencional, es decir, es correlato de la vida intencional y, por tanto, tiene un sentido secundario y relativo de un ser para la conciencia. Extendida a todo fenómeno de ser, esta es una idea que ya está contenida en el $\$ 49$ de Ideen I (Husserl, 2013: 189; Hua III/I, 105). El ser humano, dice allí, "es un ser que la conciencia pone en sus experiencias", pero más allá, entendido como una trascendencia independiente de la conciencia, es una nada o no tiene sentido. Porque entre la conciencia y la realidad "se abre un verdadero abismo de sentido". Hay que sostener que el hombre, por consiguiente, no tiene un sentido propio independiente de la conciencia. Podemos decir que al igual que el mundo, el ser humano "tiene la esencialidad de algo que por principio es SóLo algo intencional, sólo conciente, algo que es representado, que aparece conscientemente" (Husserl, 2013: 190; Hua III/I, 106).

Lo que late en ello es la teoría de la constitución y, por tanto, del sentido del ser humano. Lo que sea el ser humano, incluso desde la visión reduccionista del positivismo, y esto lo podríamos extender a cualquier punto de vista sobre el asunto (Sache), no es una cosa distinta de una "unidad de sentido", misma que presupone una conciencia que da sentido (Husserl, 2013: 204; Hua III/I, 120). Dice Husserl que realidad (Realität) y mundo (Welt), y habría que añadir aquí "ser humano" (Mensch) o inclusive aquellos conceptos relacionados como "alma” (Seele), "cuerpo" (Leib), "persona” (Person), "psique”, etcétera, son "rótulos para ciertas UNIDADES DE SENTIDO válidas, a saber, unidades del "sentido", referidas a ciertos nexos de la conciencia pura, absoluta, que conforme a su 
ESENCIA dan sentido y acreditan la validez del sentido justamente de tal manera y no de otra" (Husserl, 2013: 204; Hua III/I, 120).

\section{Dimensión trascendental}

¿Cómo se debe comprender entonces la relación que puede llegar a guardar el ser humano empírico con el sujeto trascendental? Porque es claro que hay en este planteamiento una infinidad de problemas, entre ellos los que conciernen a los de la vida trascendental, la humanidad trascendental y la persona trascendental contenidos en el tomo XXXIV de Hua. Podría decirse, sucintamente, que el ser humano empírico y el sujeto trascendental son el mismo. Y Husserl dice explícitamente en algunos lugares que así es. Pero se trata, no obstante, de una respuesta que es preciso fundamentar y que en el fondo abre toda una línea de trabajo.

En las Pariser Vorträge habla Husserl de una "escisión del yo" (Ich-Spaltung) y dice que en la reducción fenomenológica trascendental "el espectador trascendental se sitúa sobre sí mismo, se mira, y se mira como el yo entregado antes al mundo, se encuentra por ende en sí, en cuanto cogitatum, como hombre, y se encuentra en las cogitationes correspondientes el vivir y el ser trascendentales que componen lo mundano en su totalidad" (Husserl, 2009b: 16; Hua I, 16). En el mismo año de 1929, Husserl declaró en Lógica formal y lógica trascendental que la autoconstitución del ego trascendental entendido como un "ente psicofísico espacial" es "una cuestión muy oscura” (2009c: 302; Hua XVII, 246). No obstante, en las Pariser Vorträge afirma una idea que va a desarrollar y a esclarecer con un poco más de detalle en Krisis. La idea según la cual el ser humano natural ha sido, desde siempre, un sujeto trascendental, sólo que "no sabe nada de ello" (Husserl, 2009b: 16; Hua I, 16), esto es, no es consciente de su ser trascendental, por lo cual ignora lo que es. El ser humano empírico, el de la actitud natural 
entregado al mundo, antes de practicar la reducción trascendental, vive ignorando lo que vendría a ser su esencia y en lo cual recaería su racionalidad en sentido pleno: su ser trascendental como fuente última de validez de ser. El ser humano empírico vive olvidado de su ser trascendental, vive olvidando lo que es. Roberto Walton hace notar que "La constitución de todo objeto mundano implica la constitución de un yo psicofísico que es también trascendente o correlativo de la vida trascendental". Solo que, dice allí mismo: "el yo mundano es un yo trascendental que no toma conciencia de sí como trascendental porque olvida su condición de yo constituyente, $y$, por tanto, encubre que su situación mundana es el resultado de la autoconstitución externa” (2015: 313).

En la Krisis Husserl retoma esta "cuestión muy oscura” y afirma que el sujeto trascendental en su faceta de ser humano (psicofísico) se halla cautivo en el mundo; el ser humano -afirma Juan Manuel Rodríguez- es prisionero de una "comprensión mundana del ser y preso también de la mundaneidad de su propio ser" (Rodríguez, 1998: 285). Hasta podríamos decir que se trata del olvido de sí mismo como ser humano racional, porque como sujetos "funcionantes", afirma Husserl, somos todos nosotros "extra-temáticos, en cierta medida, olvidados” (Husserl, 2008: 298; Hua VI, 265).

Así, al asumir el carácter absoluto del mundo, que figura en la actitud natural como la primera evidencia apodíctica de la vida, el ser humano se olvida de sí como la fuente última de sentido y validez. Olvida que él mismo como ego trascendental es el "fundamento intencional primordial" de todo lo que tiene existencia válida para mí (Husserl, 2009c: 300; Hua XVII, 244) y que en la vida intencional de la conciencia se constituye el mundo, y él mismo como parte del mundo, como unidad intencional. En la reducción trascendental, por lo tanto, se supera la dimensión mundana del ser humano y, del mismo modo, de las ciencias naturales y humanas. La epojé fenomenológica reduce o re-con-duce el yo huma- 
no natural (“y, ciertamente, el mío” dice Husserl) al trascendental (Husserl, 2009b: 16; Hua I, 16). Pero, cabe aclarar, Husserl afirma en el Epílogo a Ideas I que este descubrimiento exige una "radical alteración de aquella actitud en que transcurre la experiencia natural, mundana" (Husserl, 2013: 468; Hua III/2, 141).

Dice Husserl en la Krisis que "Yo soy, en efecto como yo trascendental, el mismo que en la mundaneidad es un yo humano. Lo que de la humanidad estaba oculto para mí, lo descubrí en la investigación trascendental"(Husserl, 2008: 300; Hua VI, 268). Este descubrimiento, el cual se da a través de un proceso "históricomundano", enriquece la historia misma de la constitución del sentido del mundo a partir de la fenomenología trascendental, pero al revés: ¿habría que decir que enriquece al ser humano y lo posiciona en su verdadero sentido humano? ¿Cuál es esta humanidad que se descubre en la reducción trascendental? Una distinta de la humanidad natural, por supuesto, una humanidad anclada en la razón en sentido pleno. Porque la razón, como afirma Husserl en las Cartesianische Meditationen, no es el título para nada que tenga su lugar en los hechos, no es un hecho contingente de la naturaleza, " no es una facultad fáctico-accidental, no es un título para posibles hechos accidentales, sino para una estructura esencial y universal de la subjetividad trascendental' (Husserl, 2005: 100; Hua I, 92). Pero, por otro lado, esta racionalidad supone un movimiento, un despliegue histórico que la va acompañando en la forma de la teleología. Ser racional es devenir racional, es querer ser racional. Y esto es así, porque lo que está latente en el descubrimiento de esta racionalidad del ser humano, de su trascendentalidad, es este "proceso de devenir que es la autorregulación, el hacerse a sí mismo el hombre como hombre nuevo" (Husserl, 2002: 24; cfr. Hua XXVII). El descubrimiento y más aún la práctica concreta de la reducción trascendental es lo más parecido a una conversión religiosa, porque detrás de ella renace el ser humano; el hombre se renueva. 


\section{La dimensión ética de la reducción trascendental}

Lo más importante de todo es, quizás, que la reducción trascendental descubre o más bien re-con-duce al ser humano a un nivel que antes le era inaccesible. El ser humano supera su propia visión de sí mismo y descubre que ha vivido olvidado de sí. Descubre el sentido de la subjetividad trascendental como subjetividad constituyente que se despliega y se desenvuelve en el horizonte del mundo. Pero esto no implica que la práctica de la reducción sea una tarea sencilla, porque detrás de ella está una completa inversión (Umkehrung) de la vida en su actitud natural. Este cambio de actitud "plantea la más grande exigencia a la decisión y consecuencia filosóficas" (Husserl, 2008: 240; Hua VI, 204).

En efecto, habría que pensar cuál es el logro de la reducción desde un punto de vista práctico, es decir, por qué resulta importante esta Umkehrung de la vida. Si Husserl habló de su importancia al compararla, como ya hemos visto, con una "conversión religiosa” y tiempo atrás al pensarla como renovación, una renovación del hombre y de la cultura (Husserl, 2002), en la que el hombre se hace de nuevo, renace, entonces es razonable justificar la reducción trascendental desde su función ética. Y esto sería así si pensamos el cambio radical de la mirada que se lleva a cabo en el ser humano -entiéndase ahora el sujeto trascendental- en su práctica científica. Cierto es que la reducción tiene fuertes implicaciones teóricas al hacer ciencia y al buscar la verdad intentando desentrañar el sentido del mundo, pero, por ello mismo, el impacto más profundo no está en el nivel de la teoría sino en el de la praxis. Su verdadera y más clara consecuencia está en la actitud ética que se asume en la investigación científica bajo el sello de la absoluta responsabilidad, de la cual ya dice mucho la idea de la fenomenología como actitud filosófica responsable, la misma actitud que defendieron junto a Husserl, Max Scheler, Adolf Reinach, Edith Stein y muchos otros. 
Sólo así puede justificarse y entenderse por qué el filósofo, el fenomenólogo, llega a ser un funcionario de la humanidad y no uno más entre los seres que hacen o creen hacer ciencia. Sólo así se comprende la tarea de la filosofía como autorreflexión de la humanidad. Sin asumir radicalmente este cambio en el ser humano, no se puede comprender tampoco la reducción trascendental. Por ello decía Husserl que justamente el regreso del sujeto trascendental a la actitud natural ya no puede ser el mismo que era antes con su ingenuidad (Cfr. Cairns, 1976: 35). Hay en él "un movimiento admirable de su contenido anímico", pues "todo nuevo conocimiento trascendental se transforma en necesidad esencial para un enriquecimiento del contenido del alma humana" (Husserl, 2008: 300; Hua VI, 267). En este mismo sentido Roberto Walton ha hecho notar que la actitud natural es el "desde donde (Wovon-aus)" pero también el "hasta donde" (Wo-für) del filosofar" (Walton, 2015: 317). Y esto es así debido a que, como ya le señalaba Husserl a Eugen Fink, en este proceso en la que la vida trascendental se empeña en "llegar-a-ser-para-sí" se parte de la actitud natural, pero se retorna a ella finalmente también. Así, "el que filosofa cofilosofa para los otros, con los cuales se encuentra en una última comunidad de vida trascendental, pero que aún están cautivos en la situación limitada de la actitud natural" (HuaD II/1, 120, apud. Walton, 2015: 317).

Es por ello, como indica Javier San Martín, que "la antropología filosófica vive de la fenomenología trascendental" (San Martín, 2005: 72), y esto hay que tenerlo muy en cuenta para mantener un diálogo con la antropología, porque una verdadera antropología, una que sea capaz y esté dispuesta a tratar con lo humano, está obligada a ver al hombre como el sujeto trascendental que ya es. La antropología, en sentido auténtico, en sentido trascendental, no puede ser la que trata con el ser humano que se ha olvidado de lo que es, de su verdadero sentido racional y trascendental, en el que el mun- 
do figura como su correlato intencional y no como un absoluto en sí independiente o como un simple hecho del mundo.

$\mathrm{Y}$ no es un desatino formular las cosas en esta dirección. En un pasaje de la conferencia que Husserl dictó en Frankfurt, Berlín y Halle en 1931 sobre "Phänomenologie und Antropologie", con una primigenia relevancia antropológica, Husserl llega a reconocer esta "afinidad interna" (innere Affinität) que mantiene la fenomenología trascendental no sólo con la psicología sino también, dice allí, con la antropología (Hua XXVII, 181). De allí mismo se siguen las razones por las cuales ni la psicología ni la antropología deben ser vistas como ciencias positivas, pero ésta es una tarea que sólo puede llevarse a cabov a partir de "los últimos fundamentos trascendentales" (aus den letzten transzendentalen Gründen), porque sin la reducción trascendental tampoco podría alcanzarse el sentido auténtico y el valor de la antropología sino, a lo sumo, una pseudo-antropología que distorsiona el sentido de la fenomenología trascendental -aquello de lo que Husserl tanto se cuidó-. Pero, cabe aclarar, ello no desacredita en ningún sentido los logros de la investigación antropológica desde el punto de vista de la fenomenología eidética, esto es, como investigación de esencias.

\section{Consideraciones finales}

La reducción trascendental, entonces, descubre el sentido trascendental del ser humano, que lleva en sí la trascendentalidad aunque no sepa nada de ella en un primer momento. Por ello, sin comprender el sentido de la reducción no se puede hacer filosofía en serio, pero tampoco se podría comprender el sentido del ser humano como subjetividad constituyente.

Con estas declaraciones se abre aquí la posibilidad de devolverle a la filosofía, y por supuesto a la misma fenomenología, el sentido humano que había quedado olvidado detrás del proyecto científico 
de la modernidad acompañando la ingenuidad con que se vive la vida desde un inicio. Cabe recordar que Husserl no está en contra de la ciencia ni mucho menos de los logros de la misma, pero sí que es sensible al olvido de lo humano y al reduccionismo de la dimensión racional del hombre, que se resumen en el objetivismo y el naturalismo de la ciencia.

En suma, la fenomenología constituye en todos sus sentidos la más radical crítica de la razón que se ha desarrollado en la historia de la humanidad. Devolverle al hombre su verdadera humanidad, esto es, su racionalidad, ha de ser una de las tareas más nobles a las que estamos convocados todos, frente a la exigencia misma que concierne ya no sólo a la fenomenología sino al quehacer filosófico en general; esta exigencia consiste en la responsabilidad y compromiso filosófico fundados en una tarea absolutamente personal donde la epojé y la reducción se practican libremente. Por ello, la decisión de ingresar al espacio del saber reflexivo implica ya un cambio, un primer movimiento de la existencia en la búsqueda de su fundamentación.

\section{Bibliografía}

Cairns, Dorion, 1976, Conversations with Husserl and Fink, M. Nijhoff, La Haya.

Husserl, Edmund, 1965, Erste Philosophie (1923/1924), ZweiterTeil: Theoria der Phänomenologischen Reduktion, Hua VIII, R. Bohem (ed.), M. Nijhoff, La Haya.

, 1982, La idea de la fenomenología, Miguel García-Baró (trad.), FCE, México. |1973, Die Idee der Phänemonologie. Fünf Vorlesungen, Hua II, W. Biemel (ed.), M. Nijhoff, La Haya.

, 1988, Vorlesungen über Ethik und Wertlehre 1908-1914, Hua XXVIII, U. Melle (ed.), Kluwer Academic Publishers, Dordrecht. 
,2002, Renovación del hombre y de la cultura. Cinco ensayos, Agustín Serrano de Haro (trad.), UAM/Anthropos, México/ Barcelona. | 1989, Aufsätze und Vortröge (1922-1937), Hua XXVII, T. Nenon y H.R. Sepp (eds.), Academic Publishers, Kluwer Dordrecht.

2005, Meditaciones cartesianas, José Gaos y Miguel GarcíaBaró (trad.), FCE, México. | 1973, Cartesianische Meditationenen und Pariser Vorträge, Hua I, S. Strasser (ed., intro.), M. Nijhoff, La Haya.

,2006, Investigaciones lógicas, t. 1: Prolegómenos a la lógica pura, Manuel García Morante y José Gaos (versión), Alianza, Madrid. | 1975, Logische Untersuchungen. Erster Band: Prolegomena zur reinen Logik, Hua XVIII, ElmarHolenstein (ed.), M. Nijhoff, La Haya.

, 2008, La crisis de las ciencias europeas y la fenomenología trascendental, Julia V. Iribarne (trad.), Prometeo Libros, Buenos Aires. | 1976, Die Krisis der europäischen Wissenschaften und die transzendentale. Phänomenologie. Eine Einleitung in die phänomenologische Philosophie, Hua VI, W. Biemel (ed.), M. Nijhoff, La Haya.

, 2009a, La filosofía, ciencia rigurosa, Miguel García-Baró (trad.), Ediciones Encuentro, Madrid.|1987, Aufsätze und Vortröge (1922-1937), Hua XXV, T. Nenon y H.R. Sepp (eds.), Kluwer Academic Publishers, Dordrecht.

,2009b, Las conferencias de París, A. Zirión (trad.), UNAM, México. | 1973, Cartesianische Meditationene und Pariser Vorträge, Hua I, S. Strasser (ed., intro.), M. Nijhoff, La Haya.

, 2009c, Lógica formal y lógica trascendental, Luis Villoro (trad.), UNAM, México. | 1974, Formale und Tranzsendentale Logik, Paul Janssen (ed.), M. Nijhoff, La Haya.

, 2012, Las conferencias de Londres, Ramsés L. Sánchez (trad.), Sígueme, Salamanca. | 2003, Einleitung in die Philoso- 
phie. Vorlesungen 1922/23, Hua XXXV, B. Goossens (ed.), Kluwer Academic Publishers, Dordrecht.

, 2013, Ideas relativas a una fenomenología pura y una filosofía fenomenológica, libro primero: Introducción general a la fenomenología pura, Antonio Zirión (ed.), UNAM/FCE, México. | 1976, Ideen zu einer reinen Phänomenologie und phänomenologischen Philosophie. ErstesBuch: Algemeine Einfhürun in die reine Phänomenologie. Zweites Buch: Ergänzen de Texte (19121929), Karl Schuhmann (ed.), M. Nijhoff, La Haya.

,2014, Ideas relativas a una fenomenología pura y una filosofia fenomenológica, libro primero: La fenomenología y los fundamentos de las ciencias, Luis E. González (trad.), UNAM/FCE, México. | 1952, Ideen zu einer reinen Phänomenologie und phänomenologischen Philosophie. Drittes Buch: Die Phänomenologie und die Fundamente der Wissenschaften, Hua V, Marly Biemel (ed.), M. Nijhoff, La Haya.

Fink, Eugen, 2003, "La fenomenología fenomenológica de Edmund Husserl ante la crítica contemporánea", R. E. Velozo Farías (trad.), en Acta Fenomenológica Latinoamericana, vol. I, Pontificia Universidad Católica del Perú, Lima, pp. 361-428.

Mate, M.-Reyes, 1992, "Introducción. El olvido del mundo de la vida y el recuerdo del fundamento humano de la ciencia", en Edmund Husserl, Invitación a la fenomenologia, Paidós, Barcelona, pp. 9-32.

Potestà, Andrea, 2013, El origen del sentido. Husserl, Heidegger y Derrida, Metales Pesados, Santiago de Chile.

Rodríguez, José Manuel, 1998, "La epojé y la reducción fenomenológica como movimiento de evasión de la mundaneidad y conversión radical del hombre", en Fenomenología y ciencias humanas, Ma. Luz Pintos Peñaranda y José Luis González López (eds.), Universidad de Santiago de Compostela, Santiago de Compostela. 
San Martín, Javier, 1994, La fenomenología como teoría de una racionalidad fuerte, UNED, Madrid.

, 2005, Fenomenología y antropología, Lectour/UNED, Buenos Aires/Madrid.

, 2015, La nueva imagen de Husserl. Lecciones de Guanajuato, Trotta, Madrid.

Walton, Roberto, 2015, Intencionalidad y horizonticidad, Editorial Aula de Humanidades/Universidad de San Buenaventura Cali, Bogotá.

Recibido: 29 de mayo de 2017 Aceptado: 27 de noviembre de 2017 